\title{
CORRELATIONS BETWEEN ELEMENTS AND SEQUENCES IN A NUMERICAL PRISM
}

\author{
M.S. Tokmachev \\ Yaroslav-the-Wise Novgorod State University, Veliky Novgorod, Russian Federation \\ E-mail: mtokm@yandex.ru
}

A numerical prism, previously introduced by the author as an ordered set regarding the research of a three-parameter probability distribution of the hyperbolic-cosine type, which is a generalization of the known two-parameter Meixner distribution, is being considered. In geometry-related terminology, elements of a numerical prism are the coefficients of moment-forming polynomials for the specified distribution, which are obtained with the use of both differential and algebraic recurrence correlations.

Each one of the infinite number of elements depends on three indices determining its position in a prism. Fixation of one or two indices results in crosssections of the prism, which are numerical triangles or sequences. Among them, there are such well-known cross-sections as the Stirling number triangle, number triangle of coefficients in the Bessel polynomials, sequences of tangent and secant numbers, and others. However, the majority of numerical sets in the prism's cross-sections have never been described in literature before.

Considering the structure and construction algorithm, cross-sections of the numerical prism turn out to be interconnected not only by the general construction formula but also by certain correlations. As a result, formulas of connection between various groups of elements are presented in the article. In particular, expansion of secant numbers for the sum of products grouped by the number of tangent numbers' cofactors with specification of corresponding coefficients in the expansion, representation (automatic expression) of elements of a sequence of alternating secant and tangent number through the previous ones, as well as a number of other correlations for the sequences and particular elements is determined.

Keywords: hyperbolic cosine distribution; cumulants; moments; numerical prism; cross-sections; secant numbers; tangent numbers.

\section{Introduction}

We obtained the numerical set $\{U(n ; k, j)\}$ structured as a «numerical prism» in the paper [1]. The construction of the numerical prism is based on relations between the cumulants $\chi_{n}$ and the initial moments $\alpha_{n}$, where $n \in \mathbf{N}$, of the hyperbolic-cosine-type probability distribution defined $[2,3]$ by the characteristic function:

$$
f(t)=\left(\operatorname{ch} \frac{\beta}{\mu} t-i \frac{\mu}{\beta} \operatorname{sh} \frac{\beta}{m} t\right)^{-m} \text {, where } \mu, \beta, m \in \mathbf{R} ; m>0, \beta \neq 0, i=\sqrt{-1} .
$$

The obtained three-parameter distribution is described in [4] and is a generalization of the Meixner two-parameter distribution [5].

Theorem 1 ([1]). For a hyperbolic-cosine-type distribution with the characteristic function (1), the formula for calculating the cumulants $\chi_{n}, n=1,2, \ldots$, is the following:

$$
\chi_{n}=m\left(\frac{\beta}{m}\right)^{n} P_{n}\left(\frac{\mu}{\beta}\right)=m\left(\frac{\beta}{m}\right)^{n} \sum_{j=0}^{n} V(n ; j)\left(\frac{\mu}{\beta}\right)^{j},
$$

where $P_{n}(b)$ are polynomials of the form:

$$
P_{n}(b)=\sum_{j=0}^{n} V(n ; j) b^{j}, n=1,2, \ldots
$$


and the coefficients $V(n ; j)$ of the polynomials are calculated by the recurrence relation:

$$
\begin{gathered}
V(1 ; 1)=1, V(1 ; j)=0 \text { for all } j \neq 1, \\
V(n+1 ; j)=(j-1) V(n ; j-1)+(j+1) V(n ; j+1) \text { for } n \in \mathbf{N} .
\end{gathered}
$$

The polynomials $P_{n}(b)$ follow differentiation of the tangent function, and are known $[6,7]$ as $D e$ rivative polynomials.

Theorem 2 ([1]). For a hyperbolic-cosine-type distribution with the characteristic function (1), the formula for calculating the $n$-th order moments is the following:

$$
M\left(X^{n}\right)=\alpha_{n}=\left(\frac{\beta}{m}\right)^{n} P_{n}\left(m, \frac{\mu}{\beta}\right)=\left(\frac{\beta}{m}\right)^{n} \sum_{k=1}^{n} \sum_{j=0}^{n} U(n ; k, j) m^{k}\left(\frac{\mu}{\beta}\right)^{j}, n=0,1,2, \ldots,
$$

where the moment-forming polynomials of two arguments $P_{n}(m, b), n=0,1,2, \ldots$, can be represented in the form:

$$
P_{n}(m, b)=\sum_{k=1}^{n} \sum_{j=0}^{n} U(n ; k, j) m^{k} b^{j},
$$

$b \equiv \mu / \beta,\{U(n ; k, j)\}$ is a system of the integer coefficients of the polynomials related by the equations:

$$
\begin{gathered}
U(0 ; 0,0)=1, U(0 ; k, j)=0 \text { for any } k, j \neq 0, \\
U(n+1 ; k, j)=U(n ; k-1, j-1)+(j-1) U(n ; k, j-1)+(j+1) U(n ; k, j+1),
\end{gathered}
$$

for $n=0,1,2, \ldots$.

The identity $U(n ; 1, j) \equiv V(n ; j)$ follows directly from equations (4) and (7). Therefore, the numbers $V(n ; j)$ are only special cases of numbers $U(n ; k, j)$ for $k=1$.

For each fixed $k$, where $k \in \mathbf{N}$, the corresponding subset of $\{U(n ; k, j)\}$ forms a numerical triangle. In terms of geometry, the set $\{U(n ; k, j)\}$ is a set of numerical triangles ordered by $k$, and can be considered as a «numerical prism», where for each given $k$ the triangle is a section of the prism $[1,8]$. Similarly, we can obtain sections of the prism by fixing the argument $j, j=0,1,2, \ldots$. These sets are usually novel.

Let us either fix two of the parameters $n, k, j$, or express two of them through the remaining parameter. The numerical sequences obtained in the numerical prism include many well-known sequences (tangent numbers, secant numbers, Stirling numbers of the first kind, coefficients in expansions of various functions, for example, in the Bessel polynomials, etc.) [9]. However, the overwhelming majority of the obtained sequences is not mentioned in the literature. The issue of novelty is solved with the help of a sufficiently complete on-line encyclopedia of integer sequences (OEIS) [10].

We notice the lasting interest in numerical sequences and triangles. For example, the paper [11] presents a numerical pyramid which sections are known numerical sets: those of Deleham, Euler, MacMahon, Stirling. Also, the paper [11] gives a series of numerical sequences, among which only the sequences A000182, A000184, A00147, and A085734 in OEIS are common with the numerical prism. Other sequences and triangles are also present as subsets in the considered numerical prism. The paper [12] identifies the first elements of the numerical triangle $\{U(n ; 1, j)\}$ as the numbers $T_{n, k}$ calculated by the recurrence relation $T_{n, k}=\delta_{1 k}, T_{n+1, k}=(k-1) T_{n, k-1}+(k+1) T_{n, k+1}$. This is a special case of relation (7). Along with interest in finding new numerical sequences, there is an increasing interest in classical sets of numbers considered from different points of view. In particular, the paper [13] presents simple and asymptotically fast algorithms for calculating tangent and secant numbers. In the considered numerical prism, we can not only easily calculate these sequences, but also establish structural relations between the sequences.

\section{Cumulants and moments in the numerical prism structure}

Therefore, the considered numerical prism is an ordered set $\{U(n ; k, j)\}$ of the coefficients of the polynomials $P_{n}(b)$ and $P_{n}(m, b)$ that form, respectively, the cumulants and moments of the hyperboliccosine-type probability distribution [1]. Moreover, according to (2) and in view of the equality 


\section{Математика}

$U(n ; 1, j) \equiv V(n ; j)$, the distribution cumulants are completely determined by the distribution parameters $\mu, \beta, m$ and the set of coefficients $\{U(n ; 1, j)\}$ :

$$
\chi_{n}=m\left(\frac{\beta}{m}\right)^{n} P_{n}\left(\frac{\mu}{\beta}\right)=m\left(\frac{\beta}{m}\right)^{n} \sum_{j=0}^{n} V(n ; j)\left(\frac{\mu}{\beta}\right)^{j}=m\left(\frac{\beta}{m}\right)^{n} \sum_{j=0}^{n} U(n ; 1, j) b^{j} \text {, where } b=\frac{\mu}{\beta} .
$$

For $n=\overline{1,12}, j=\overline{0,10}$, the corresponding section $\{U(n ; 1, j)\}$ is partially presented in table 1 . According to (7), subsequent values are calculated simply, without using differential relations. Note that the section $\{U(n ; 1, j)\}$ is the known [10:A008293] triangle of coefficients in the expansion of $\operatorname{tg}^{(n)} x$ in powers of $\operatorname{tg} x$.

Table 1

Section $\{U(n ; 1, j)\}$ of the numerical prism

\begin{tabular}{|l|c|c|c|c|c|c|c|c|c|c|c|}
\hline $\boldsymbol{n}$ & $\mathbf{0}$ & $\mathbf{1}$ & $\mathbf{2}$ & $\mathbf{3}$ & $\mathbf{4}$ & $\mathbf{5}$ & $\mathbf{6}$ & $\mathbf{7}$ & $\mathbf{8}$ & $\mathbf{9}$ & $\mathbf{1 0}$ \\
\hline $\mathbf{1}$ & & 1 & & & & & & & & & \\
\hline $\mathbf{2}$ & 1 & & 1 & & & & & & & & \\
\hline $\mathbf{3}$ & & 2 & & 2 & & & & & & & \\
\hline $\mathbf{4}$ & 2 & & 8 & & 6 & & & & & & \\
\hline $\mathbf{5}$ & & 16 & & 40 & & 24 & & & & & \\
\hline $\mathbf{6}$ & 16 & & 136 & & 240 & & 120 & & & & \\
\hline $\mathbf{7}$ & & 272 & & 1232 & & 1680 & & 720 & & & \\
\hline $\mathbf{8}$ & 272 & & 3968 & & 12096 & & 13440 & & 5040 & & \\
\hline $\mathbf{9}$ & & 7936 & & 56320 & & 129024 & & 120960 & & 40320 & \\
\hline $\mathbf{1 0}$ & 7936 & & 176896 & & 814080 & & 1491840 & & 1209600 & & 362880 \\
\hline $\mathbf{1 1}$ & & 353792 & & 3610112 & & 12207360 & & 18627840 & & 13305600 & \\
\hline $\mathbf{1 2}$ & 353792 & & 11184128 & & 71867136 & & 191431680 & & 250145280 & & 159667200 \\
\hline
\end{tabular}

In order to calculate the initial moments $\alpha_{n}$ of the hyperbolic-cosine-type distribution (see (5)), we use the parameters $\mu, \beta, m$ along with all sections of the numerical prism $\{U(n ; k, j)\}$ determined by $k$, where $k=\overline{1, n}$.

Let us consider the relation between the moments and cumulants with reference to the set $\{U(n ; k, j)\}$.

As is well known, the moments $\left\{\alpha_{n}\right\}$ and cumulants $\left\{\chi_{s}\right\}$ of probability distributions are connected by the following polynomial relations:

$$
\begin{gathered}
\alpha_{1}=\chi_{1} ; \\
\alpha_{2}=\chi_{2}+\chi_{1}^{2} ; \\
\alpha_{3}=\chi_{3}+3 \chi_{1} \chi_{2}+\chi_{1}^{3} \\
\alpha_{5}=\chi_{5}+\left(5 \chi_{1} \chi_{4}+10 \chi_{4} \chi_{3}\right)+\left(3 \chi_{2}^{2}+4 \chi_{1} \chi_{3}\right)+6 \chi_{1}^{2} \chi_{2}+\chi_{1}^{4} ; \\
\alpha_{6}=\chi_{6}+\left(6 \chi_{1} \chi_{5}+15 \chi_{2} \chi_{2}^{2}\right)+10 \chi_{1}^{3} \chi_{2}+\chi_{1}^{5} ; \\
\left.+\left(20 \chi_{1}^{3} \chi_{3}+45 \chi_{1}^{2} \chi_{2}^{2}\right)+15 \chi_{1}^{2} \chi_{4}+60 \chi_{1} \chi_{2} \chi_{3}+15 \chi_{2}^{3}\right)
\end{gathered}
$$

In the above expressions, the terms are grouped according to the number of cumulants-factors in the product. For any $n, n \in \mathbf{N}$, the relation takes the form:

$$
\alpha_{n}=\sum_{k=1}^{n} \sum_{\substack{s_{1}+s_{2}+\ldots+s_{k}=n \\ s_{i} \neq 0}} a_{s_{1}, s_{2}, \ldots, s_{k}} \chi_{s_{1}} \chi_{s_{2}} \ldots \chi_{s_{k}}
$$


where $k$ is the number of the multiplied cumulants, $a_{s_{1}, s_{2}, \ldots, s_{k}}$ are the corresponding coefficients at the products $\chi_{s_{1}} \chi_{s_{2}} \ldots \chi_{s_{k}}$, and $s_{i}$ is the order of the cumulant $\chi_{s_{i}}$.

Theorem 3. For the hyperbolic-cosine-type distribution, consider the decomposition of the initial moments $\alpha_{n}$ into sum (10) of the cumulant products with given coefficients. Then the number of cumulants-factors in the corresponding terms is determined by the parameter $k$ in the formula:

$$
\alpha_{n}=\left(\frac{\beta}{m}\right)^{n} \sum_{k=1}^{n} m^{k} \sum_{j=0}^{n} U(n ; k, j) b^{j} .
$$

Proof. As it follows from (5), (10),

$$
\alpha_{n}=\left(\frac{\beta}{m}\right)^{n} \sum_{k=1}^{n} \sum_{j=0}^{n} U(n ; k, j) m^{k} b^{j}=\sum_{k=1}^{n} \sum_{\substack{s_{1}+s_{2}+\ldots+s_{k}=n, s_{i} \neq 0}} a_{s_{1}, s_{2}, \ldots, s_{k}} \chi_{s_{1}} \chi_{s_{2}} \ldots \chi_{s_{k}} .
$$

According to (8), the cumulants considered in (12) can be represented as:

$$
\chi_{s_{i}}=m\left(\frac{\beta}{m}\right)^{s_{i}} \sum_{j=0}^{s_{i}} U\left(s_{i} ; 1, j\right) b^{j} .
$$

Note that, regardless of the order $s_{i}$ of the cumulant, there is a factor $m$ in equation (13). Consequently, there is a factor $m^{k}$ in each product of $k$ cumulants, despite of different orders $s_{1}, s_{2}, \ldots, s_{k}$ of the cumulants $\chi_{s_{1}} \chi_{s_{2}} \ldots \chi_{s_{k}}$.

Substitute the cumulants in the form of (13) into the right side of (12):

$$
\alpha_{n}=\left(\frac{\beta}{m}\right)^{n} \sum_{k=1}^{n} \sum_{j=0}^{n} U(n ; k, j) m^{k} b^{j}=\sum_{k=1}^{n} \sum_{\substack{s_{1}+s_{2}+\ldots+s_{k}=n, s_{i} \neq 0}} a_{s_{1}, s_{2}, \ldots, s_{k}} \prod_{i=1}^{k}\left[\left(\frac{\beta}{m}\right)^{s_{i}} m \sum_{j=0}^{s_{i}} U\left(s_{i} ; 1, j\right) b^{j}\right],
$$

i.e.

$$
\alpha_{n}=\left(\frac{\beta}{m}\right)^{n} \sum_{k=1}^{n} m^{k} \sum_{j=0}^{n} U(n ; k, j) b^{j}=\left(\frac{\beta}{m}\right)^{n} \sum_{k=1}^{n} m^{k} \sum_{\substack{s_{1}+s_{2}+\ldots+s_{k}=n, s_{i} \neq 0}} a_{s_{1}, s_{2}, \ldots, s_{k}} \prod_{i=1}^{k}\left[\sum_{j=0}^{s_{i}} U\left(s_{i} ; 1, j\right) b^{j}\right],
$$

where each term of the polynomials of variables $m$ and $b$ on the right side of (14) is such that the parameter $k$ of $m^{k}$ indicates the number of cumulants-factors in the corresponding product. Since the polynomials on both sides of (14) are equal, coefficients at the same powers of $m$ are also equal. Then, the following equality holds for any $m$ :

$$
m^{k}\left(\frac{\beta}{m}\right)^{n} \sum_{j=0}^{n} U(n ; k, j) b^{j}=\left(\frac{\beta}{m}\right)^{n} m^{k} \sum_{\substack{s_{1}+s_{2}+\ldots+s_{k}=n, s_{i} \neq 0}} a_{s_{1}, s_{2}, \ldots, s_{k}} \prod_{i=1}^{k}\left[\sum_{j=0}^{s_{i}} U\left(s_{i} ; 1, j\right) b^{j}\right] .
$$

Therefore,

$$
m^{k}\left(\frac{\beta}{m}\right)^{n} \sum_{j=0}^{n} U(n ; k, j) b^{j}=\sum_{\substack{s_{1}+s_{2}+\ldots+s_{k}=n, s_{i} \neq 0}} a_{s_{1}, s_{2}, \ldots, s_{k}} \chi_{s_{1}} \chi_{s_{2}} \ldots \chi_{s_{k}} \text { for } k=1,2, \ldots, n .
$$

At the same time, the power $k$ and number of cumulants in the product are equal for each term on the right side of the equation.

This completes the proof of Theorem 3.

Theorem 4 . There are the following relations for coefficients of the polynomials $P_{n}(m, b)$ :

$$
\sum_{j=0}^{n} U(n ; k, j) b^{j}=\sum_{\substack{s_{1}+s_{2}+\ldots . s_{k}=n, s_{i} \neq 0}} a_{s_{1}, s_{2}, \ldots, s_{k}} \prod_{i=1}^{k}\left[\sum_{j=0}^{s_{i}} U\left(s_{i} ; 1, j\right) b^{j}\right], \text { where } k=\overline{1, n} .
$$

Proof. Divide both sides of $(15)$ by $(\beta / m)^{n}$ and compare expressions of the same powers of $m$ in the polynomials. 


\section{Математика}

Corollary 4.1. For any $b$, the following condition holds for the section $\{U(n ; 2, j)\}$ of the numerical prism:

$$
\sum_{j=0}^{n} U(n ; 2, j) b^{j}=\sum_{\substack{s+l=n, s, l \neq 0}} a_{s, l}\left[\sum_{j_{s}=0}^{s} U\left(s ; 1, j_{s}\right) b^{j_{s}}\right] \cdot\left[\sum_{j_{l}=0}^{l} U\left(l ; 1, j_{l}\right) b^{j_{l}}\right] .
$$

In particular, compare coefficients of the same powers of $b$ in the polynomials and obtain:

$$
U(n ; 2, j)=\sum_{\substack{s+l=n, s, l \neq 0}} a_{s, l}\left[\sum_{j_{s}+j_{l}=j} U\left(s ; 1, j_{s}\right) \cdot U\left(l ; 1, j_{l}\right)\right], \text { where } j=\overline{0, n} .
$$

Corollary 4.2. For any $b$, the following condition holds for the section $\{U(n ; 3, j)\}$ of the numerical prism:

$$
\sum_{j=0}^{n} U(n ; 3, j) b^{j}=\sum_{\substack{i+s+l=n, i, s, l \neq 0}} a_{i, s, l}\left[\sum_{j_{i}=0}^{i} U\left(i ; 1, j_{i}\right) b^{j_{i}}\right]\left[\sum_{j_{s}=0}^{s} U\left(s ; 1, j_{s}\right) b^{j_{s}}\right] \cdot\left[\sum_{j_{l}=0}^{l} U\left(l ; 1, j_{l}\right) b^{j_{l}}\right] .
$$

In particular, compare coefficients of the same powers of $b$ in the polynomials and obtain:

$$
U(n ; 3, j)=\sum_{\substack{i+s+l=n, i, s, l \neq 0}} a_{i, s, l}\left[\sum_{j_{i}+j_{s}+j_{l}=j} U\left(i ; 1, j_{i}\right) \cdot U\left(s ; 1, j_{s}\right) \cdot U\left(l ; 1, j_{l}\right)\right] \text {, where } j=\overline{0, n} .
$$

Corollary 4.3. If $b=1$, then relation (16) implies the following relation for coefficients of the polynomials $P_{n}(m, b)$ :

$$
\sum_{j=0}^{n} U(n ; k, j)=\sum_{\substack{s_{1}+s_{2}+\ldots+s_{k}=n, s_{i} \neq 0}} a_{s_{1}, s_{2}, \ldots, s_{k}} \prod_{i=1}^{k}\left[\sum_{j_{i}=0}^{s_{i}} U\left(s_{i} ; 1, j_{i}\right)\right], \text { where } k=\overline{1, n} .
$$

Corollary 4.4. If $b=0$, then relation (16) implyies the following relation for coefficients of the polynomials $P_{n}(m, b)$ :

In particular,

$$
U(n ; k, 0)=\sum_{\substack{s_{1}+s_{2}+\ldots+s_{k}=n, s_{i} \neq 0}} a_{s_{1}, s_{2}, \ldots, s_{k}} \prod_{i=1}^{k} U\left(s_{i} ; 1,0\right), \text { where } k=\overline{1, n}
$$

$$
\begin{gathered}
U(n ; 1,0)=\sum_{s_{1}=n,} a_{s_{1}} U\left(s_{1} ; 1,0\right)=U(n ; 1,0) ; \\
U(n ; 2,0)=\sum_{\substack{s+l=n, s, l \neq 0}} a_{s, l} U(s ; 1,0) U(l ; 1,0) ; \\
U(n ; 3,0)=\sum_{\substack{i+s+l=n, i, s, l \neq 0}} a_{i, s, l} U(i ; 1,0) \cdot U(s ; 1,0) \cdot U(l ; 1,0) .
\end{gathered}
$$

Corollary 4.5. If $b=0$, then the following relation is obtained from (22) by summation over $k$ :

$$
\sum_{k=1}^{n} U(n ; k, 0)=\sum_{k=1}^{n} \sum_{\substack{s_{1}+s_{2}+\ldots+s_{k}=n, s_{i} \neq 0}} a_{s_{1}, s_{2}, \ldots, s_{k}} \prod_{i=1}^{k} U\left(s_{i} ; 1,0\right) .
$$

Theorem 5. In a section of the numerical $\operatorname{prism}\{U(n ; k, j)\}$, the numerical triangle $\{U(2 n ; k, 0)\}$ is a decomposition of the secant numbers $\left\{E_{n}\right\}$ into the sum of products grouped by the number of factors of the tangent numbers $\left\{T_{n}\right\}$. Namely, 


$$
E_{0}=1, E_{n}=\sum_{k=1}^{n} \sum_{\substack{2 s_{1}+2 s_{2}+\ldots+2 s_{k}=2 n, s_{i} \neq 0}} a_{2 s_{1}, 2 s_{2}, \ldots, 2 s_{k}} T_{s_{1}} \cdot T_{s_{2}} \cdot \ldots \cdot T_{s_{k}},
$$

where $n \in \mathbf{N}, a_{2 s_{1}, 2 s_{2}, \ldots, 2 s_{k}}$ are the positive integer coefficients in the representation, see (9), of the initial probability moments $\alpha_{2 n}=E_{n}$ as the sum of products of the cumulants $\chi_{1}, \chi_{2}, \ldots, \chi_{2 n}$ ( $2 s_{1}, 2 s_{2}, \ldots, 2 s_{k}$ are even orders of the multiplied cumulants).

Proof. According to [8], if the parameters of the hyperbolic-cosine-type distribution are $\mu=0, \beta=1, m=1$, then the cumulants $\left\{\chi_{2 n}\right\}$ are tangent numbers $\chi_{2 n}=T_{n}, n \in \mathbf{N}$, and the initial moments $\left\{\alpha_{2 n}\right\}$ are secant numbers: $E_{0}=1, \alpha_{2 n}=E_{n}$, for $n \in \mathrm{N}$. In addition, for $\mu=0, \beta=1, m=1$, relation (13) implies that:

and relation (11) implies that:

$$
\chi_{2 n}=U(2 n ; 1,0), \chi_{2 n-1}=U(2 n-1 ; 1,0)=0 ;
$$

$$
\alpha_{2 n}=\sum_{k=1}^{2 n} U(2 n ; k, 0), \alpha_{2 n-1}=\sum_{k=1}^{2 n-1} U(2 n-1 ; k, 0)=0,
$$

since $U(2 n-1 ; k, 0)=0$ for $n, k \in \mathbf{N}$.

We use relation (25) only for even $n$ and $s_{i}$ (since $U(n ; k, 0)$ and $U\left(s_{i} ; 1,0\right)$ are equal to zero, if $n$ and $s_{i}$ are odd). Redesignate the indices and obtain:

$$
\sum_{k=1}^{2 n} U(2 n ; k, 0)=\sum_{k=1}^{2 n} \sum_{\substack{2 s_{1}+2 s_{2}+\ldots+2 s_{k}=2 n, s_{i} \neq 0}} a_{2 s_{1}, 2 s_{2}, \ldots, 2 s_{k}} \prod_{i=1}^{k} U\left(2 s_{i} ; 1,0\right) .
$$

For nonzero summation indices, if $2 s_{1}+2 s_{2}+\ldots+2 s_{k}=2 n$, i.e. $s_{1}+s_{2}+\ldots+s_{k}=n$, then $k \leq n$. Consequently, in the equality above, the summation over $k$ is conducted from 1 to $n$. Therefore,

$$
\sum_{k=1}^{n} U(2 n ; k, 0)=\sum_{k=1}^{n} \sum_{\substack{2 s_{1}+2 s_{2}+\ldots+2 s_{k}=2 n, s_{i} \neq 0}} a_{2 s_{1}, 2 s_{2}, \ldots, 2 s_{k}} \prod_{i=1}^{k} U\left(2 s_{i} ; 1,0\right),
$$

i. e.

$$
\alpha_{2 n}=\sum_{k=1}^{n} \sum_{\substack{2 s_{1}+2 s_{2}+\ldots+2 s_{k}=2 n, s_{i} \neq 0}} a_{2 s_{1}, 2 s_{2}, \ldots, 2 s_{k}} \prod_{i=1}^{k} \chi_{2 s_{i}} .
$$

Replace the moments and cumulants by the corresponding secant and tangent numbers $\alpha_{2 n}=E_{n}$, $\chi_{2 s_{i}}=T_{s_{i}}$ in (28). We arrive at relation (26):

$$
E_{n}=\sum_{k=1}^{n} \sum_{\substack{2 s_{1}+2 s_{2}+\ldots+2 s_{k}=2 n, s_{i} \neq 0}} a_{2 s_{1}, 2 s_{2}, \ldots, 2 s_{k}} T_{s_{1}} \cdot T_{s_{2}} \cdot \ldots \cdot T_{s_{k}} .
$$

This completes the proof of Theorem 5.

Theorem 6 . For fixed $k, k=1,2, \ldots, 2 n$, each of sequences $\{U(2 n ; k, 0)\}$ is a sequence of such terms in the decomposition of secant numbers $\left\{E_{n}\right\}$ that contain $k$ factors consisting of tangent numbers. Namely,

$$
\begin{gathered}
U(2 n ; k, 0)=\sum_{\substack{2 s_{1}+2 s_{2}+\ldots+2 s_{k}=2 n, s_{i} \neq 0}} a_{2 s_{1}, 2 s_{2}, \ldots, 2 s_{k}} T_{s_{1}} \cdot T_{s_{2}} \cdot \ldots \cdot T_{s_{k}}, \\
E_{n}=\sum_{k=1}^{n} U(2 n ; k, 0),
\end{gathered}
$$

where $\left\{T_{i}\right\}$ are tangent numbers, $a_{2 s_{1}, 2 s_{2}, \ldots, 2 s_{k}}$ are positive integer coefficients in the representation, see (9), of the initial moments $\alpha_{2 n}=E_{n}$ as the sum of products of the cumulants $\chi_{1}, \chi_{2}, \ldots, \chi_{2 n}$. 


\section{Математика}

Proof. In order to obtain equation (29), replace $n$ by $2 n$ in (22) and use relation (27), where $\chi_{2 s_{i}}=T_{s_{i}}$. Relation (30) follows from (26) and (29).

Corollary 6.1. The sequence $\{U(2 n ; 1,0)\}$ is a sequence of the tangent numbers $\left\{T_{n}\right\}$.

The statement directly follows from (29), since $2 s_{1}+2 s_{2}+\ldots+2 s_{k}=2 n, a_{2 s_{1}, 2 s_{2}, \ldots, 2 s_{k}} \equiv a_{2 n}$ for $k=1$, and all coefficients $a_{2 n}$ of the highest cumulants $\chi_{2 n}$ in formulas (9) are equal to 1 .

Corollary 6.2. The sequence $\{U(2 n ; 2,0)\}$ satisfies the following relation:

$$
U(2 n ; 2,0)=\sum_{\substack{2 s+2 l=2 n, s, l \neq 0}} a_{2 s, 2 l} U(2 s ; 1,0) U(2 l ; 1,0)=\sum_{\substack{2 s+2 l=2 n, s, l \neq 0}} a_{2 s, 2 l} T_{s} \cdot T_{l} .
$$

The statement is a special case of (29) and (23), since $T_{s}=\chi_{2 s}=U(2 s ; 1,0)$ for any $s, s \in \mathrm{N}$.

Corollary 6.3 . The sequence $\{U(2 n ; 3,0)\}$ satisfies the following relation:

$$
U(2 n ; 3,0)=\sum_{\substack{2 i+2 s+2 l=2 n, i, s, l \neq 0}} a_{2 i, 2 s, 2 l} U(2 i ; 1,0) \cdot U(2 s ; 1,0) \cdot U(2 l ; 1,0)=\sum_{\substack{2 i+2 s+2 l=2 n, i, s, l \neq 0}} a_{2 i, 2 s, 2 l} T_{i} \cdot T_{s} \cdot T_{l} .
$$

The statement is a special case of (29) and (24), since $T_{s}=\chi_{2 s}=U(2 s ; 1,0)$ for any $s, s \in \mathrm{N}$.

Using the formulas for representation of cumulants in terms of moments, we can also obtain inverse relations expressing the tangent numbers $\left\{T_{i}\right\}$ in terms of the secant numbers $\left\{E_{n}\right\}$ indicated in the section $\{U(n ; k, 0)\}$.

By analogy with Theorems 5 and 6 , we can also represent relations between other sequences. Let us give two examples. Let $\mu=1, \beta=1, m=1$. Then cumulants and moments of distribution connected by mutually inverse relations are the sequence $(1,2,4,16,80,512,3904,34816, \ldots)[10: A 000831]$ and the sequence $(1,1,3,11,57,361,2763,24611, \ldots)$ [10: $A 001586]$, respectively. The latter sequence is given by generalized Euler numbers. For $\mu=1, \beta=1, m=2$, a sequence of cumulants, i.e. a sequence of alternating secant and tangent numbers, and a sequence of moments are equal up to a shift on two positions: $\chi_{k}=\alpha_{k-2}, k=2,3, \ldots$ [8]. Therefore, this sequence can be restored by the previous elements (autoexpression). If we know the structure (representation of cumulants through moments and, conversely, moments through cumulants), then we can use the numerical prism to find specific terms in the expression of each sequence through its pair sequence.

Remark 1. For $2 n \leq 12$, if all moments and cumulants of odd order are equal to zero, then the coefficients $a_{2 s_{1}, 2 s_{2}, \ldots, 2 s_{k}}$ used in the formulas to connect moments and cumulants of even order are as follows:

$$
\begin{gathered}
\alpha_{2}=\chi_{2} ; \\
\alpha_{4}=\chi_{4}+\left(3 \chi_{2}^{2}\right) ; \\
\alpha_{6}=\chi_{6}+\left(15 \chi_{2} \chi_{4}\right)+\left(15 \chi_{2}^{3}\right) ; \\
\alpha_{8}=\chi_{8}+\left(28 \chi_{2} \chi_{6}+35 \chi_{4}^{2}\right)+\left(210 \chi_{2}^{2} \chi_{4}\right)+\left(105 \chi_{2}^{4}\right) ; \\
\alpha_{12}=\chi_{10}+\left(45 \chi_{12} \chi_{8}+210 \chi_{4} \chi_{6}\right)+\left(630 \chi_{2}^{2} \chi_{6}+1575 \chi_{10}+462 \chi_{6}^{2}+495 \chi_{4} \chi_{8}\right)+\left(1485 \chi_{2}^{2} \chi_{8}+13860 \chi_{2} \chi_{4} \chi_{6}+5775 \chi_{4}^{3}\right)+\left(945 \chi_{2}^{5}\right) ; \\
+\left(13860 \chi_{2}^{3} \chi_{6}+51975 \chi_{2}^{2} \chi_{4}^{2}\right)+\left(51975 \chi_{2}^{4} \chi_{4}\right)+\left(10395 \chi_{2}^{6}\right) ;
\end{gathered}
$$

Remark 2. In order to illustrate the theory, the fragment of section $\{U(n ; k, 0)\}$ of the numerical prism is given in table 2 (initial values for $n=\overline{1,16}, k=\overline{1,8}$ ). The rows present terms in the expansion of secant numbers by tangent numbers.

\section{Conclusion}

In the present work, the structured values of the numerical prism result in different relations and regularities in the field of numbers. At the same time, the numerical set $\{U(n ; k, j)\}$ has other applica- 
tions. For example, for given coefficients $\{U(n ; k, j)\}$ and formulas for the density of the hyperboliccosine-type distribution [14], we can use the relation between the initial moments and derivatives of the characteristic function in order to obtain analytically values of improper integrals for a certain class of functions. For the parameters $\mu, \beta, m$, the papers [15-17] present the general form of exact formulas for the integrals of expressions containing a beta function with complex-conjugate variable arguments. In particular, according to [16], values of the integrals of a combination of a power function, an exponential function, a hyperbolic secant or cosecant, and some polynomials with different parameters are obtained for $m \in \mathrm{N}$.

Table 2

Section $\{U(n ; k, 0)\}$ of the numerical prism

\begin{tabular}{|c|c|c|c|c|c|c|c|c|}
\hline$n$ & 1 & 2 & 3 & 4 & 5 & 6 & 7 & 8 \\
\hline \multicolumn{9}{|l|}{1} \\
\hline 2 & 1 & & & & & & & \\
\hline \multicolumn{9}{|l|}{3} \\
\hline 4 & 2 & 3 & & & & & & \\
\hline \multicolumn{9}{|l|}{5} \\
\hline 6 & 16 & 30 & 15 & & & & & \\
\hline \multicolumn{9}{|l|}{7} \\
\hline 8 & 272 & 588 & 420 & 105 & & & & \\
\hline \multicolumn{9}{|l|}{9} \\
\hline 10 & 7936 & 18960 & 16380 & 6300 & 945 & & & \\
\hline \multicolumn{9}{|l|}{11} \\
\hline 12 & 353792 & 911328 & 893640 & 429660 & 103950 & 10395 & & \\
\hline \multicolumn{9}{|l|}{13} \\
\hline 14 & 22368256 & 61152000 & 65825760 & 36636600 & 11351340 & 1891890 & 135135 & \\
\hline \multicolumn{9}{|l|}{15} \\
\hline 16 & 1903757312 & 5464904448 & 6327135360 & 3918554640 & 1427025600 & 310269960 & 37837800 & 2027025 \\
\hline
\end{tabular}

Therefore, the integer set $\{U(n ; k, j)\}$ introduced from probabilistic considerations is also of independent interest for mathematical analysis, number theory, coding theory, etc. A number of relations of the numerical prism and more detailed initial fragments of sections are presented in the author's monograph [17].

\section{References}

1. Tokmachev M.S. Calculation of cumulants and moments of the Meixner distribution. Bulletin of the Novgorod State University, 2013, no. 75-2, pp. 47-51. (in Russ.).

2. Tokmachev M.S. Dep. in VINITI, 21.06.94, no. 1542, B94, 11 p. (in Russ.).

3. Tokmachev M.S. Postoyanstvo regressii kvadratichnoy statistiki na lineynuyu statistiku (A constant regression of a quadratic statistics on a linear statistics). Bulletin of the Novgorod State University, 1995, no. 1, pp. 139-141. (in Russ.).

4. Tokmachev M.S., Tokmachev A.M. Raspredelenie tipa giperbolicheskogo kosinusa (A distribution of the hyperbolic cosine type). Bulletin of the Novgorod State University, 2001, no. 17, pp. 85-88. (in Russ.).

5. Lai C.D. Meixner Classes and Meixner Hyper-Geometric Distributions. Australian \& New Zealand Journal of Statistics, 1982, Vol. 24, Issue 2, pp. 221-233. DOI: 10.1111/j.1467842X.1982.tb00828.x

6. Hoffman M.E. Derivative polynomials for tangent and secant. The American Mathematical Monthly, 1995, Vol. 102, no. 1, pp. 23-30. DOI: 10.2307/2974853

7. Hoffman M.E. Derivative polynomials, Euler polynomials, and associated integer sequences. Electronic Journal of Combinatorics, 1999, Vol. 6, \#R21

8. Tokmachev M.S. About number sets and sequences in connection with a distribution of the hyperbolic cosine type. Vestnik NovSU. Issue: Physico-Mathematical Sciences, 2015, no. 3(86), part 2, pp. 35-39. (in Russ.). 


\section{Математика}

9. Tokmachev M.S. Dep. in VINITI, 09.06.2016, no. 91-B2016, 90 p. (in Russ.).

10. The On-Line Encyclopedia of Integer Sequences ${ }^{\mathrm{TM}}$ (OEIS $\left.{ }^{\mathrm{TM}}\right)$. http://oeis.org (last access: 5.05.2018).

11. Franssens G.R. On a Number Pyramid Related to the Binomial, Deleham, Eulerian, MacMahon and Stirling number triangles. Journal of Integer Sequences, 2006, Vol. 9, Issue 1, Article 06.4.1. http://www.cs.uwaterloo.ca/journals/JIS

12. Knuth D.E., Buckholtz T.J., Computation of tangent, Euler and Bernoulli numbers. Math. Comp., 1967, Vol. 21, pp. 663-688. DOI: 10.1090/S0025-5718-1967-0221735-9

13. Brent R.P., Harvey D. Fast computation of Bernoulli, Tangent and Secant numbers. arXiv preprint, 2011, arXiv:1108.0286 [math.CO].

14. Tokmachev M.S. Prikladnoy aspekt obobshchennogo raspredeleniya giperbolicheskogo kosinusa (Applications of the generalized hyperbolic cosine distribution). Bulletin of the Novgorod State University, 2005, no. 34, pp. 96-99 (in Russ.).

15. Tokmachev, M.S. Nekotorye integraly, svyazannye s raspredeleniem tipa giperbolicheskogo kosinusa (Some integrals related to the hyperbolic cosine type distribution). Matematika $v$ vuze $i v$ shkole: Trudy XXIV Mezhdunarodnoy nauchno-metodicheskoy konferentsii (Mathematics in high school and in school: Proceedings of the XXIV International Scientific and Methodical Conference), St. Petersburg, Petersburg state transport university, 2012, pp. 185-186. (in Russ.).

16. Tokmachev M.S. Evaluation of integrals for some class of functions with probabilistic interpretation. Vestnik NovSU. Issue: Physico-Mathematical Sciences, 2014, no. 80, pp. 42-46. (in Russ.).

17. Tokmachev M.S. Veroyatnostnye raspredeleniya: ot kharakterizatsii $k$ chislovym mnozhestvam (Probability distributions: from characterization to numerical sets). Saarbryukken, LAP LAMBERT Publ., 2018, 224 p. (in Russ.).

Received December 7, 2018

Bulletin of the South Ural State University Series "Mathematics. Mechanics. Physics" 2019, vol. 11, no. 1, pp. 24-33

\section{СООТНОШЕНИЯ ЭЛЕМЕНТОВ И ПОСЛЕДОВАТЕЛЬНОСТЕЙ В ЧИСЛОВОЙ ПРИЗМЕ}

\section{М.С. Токмачев}

Новгородский государственный университет им. Ярослава Мудрого, г. Великий Новгород, Российская Федерация

E-mail:mtokm@yandex.ru

Рассматривается числовая призма, ранее введенная автором как упорядоченное множество в связи с исследованием трехпараметрического вероятностного распределения типа гиперболического косинуса, являющегося обобщением известного двухпараметрического распределения Майкснера. В геометрической терминологии элементы числовой призмы - коэффициенты моментообразующих полиномов для указанного распределения, которые получаются с помощью как дифференциальных, так и алгебраических рекуррентных соотношений.

Каждый из бесконечного количества элементов зависит от трех индексов, которые и определяют его местоположение в призме. При фиксировании одного или двух индексов получаются сечения призмы: числовые треугольники или числовые последовательности. Среди сечений имеются широко известные, например, числовой треугольник Стирлинга, числовой треугольник коэффициентов в полиномах Бесселя, последовательности тангенциальных и секансных чисел и др. Однако подавляющее большинство числовых множеств в сечениях призмы ранее в литературе не встречались.

Ввиду структуры и алгоритма построения, сечения числовой призмы оказываются связанными между собой не только общей формулой построения, но и определенными соотношениями. Как результат, в статье представлены формулы связи между различными группами элементов. 
В частности, найдены разложение секансных чисел на сумму произведений, сгруппированных по количеству сомножителей тангенциальных чисел с указанием соответствующих коэффициентов в разложении, представление (автовыражение) элементов последовательности чередующихся секансных и тангенциальных чисел через свои предыдущие, а также ряд других соотношений для последовательностей и отдельных элементов.

Ключевые слова: распределение типа гиперболического косинуса; кумулянты; моменты; числовая призма; сечения; секансные числа; тангенциальные числа.

\section{Литература}

1. Токмачев, М.С. Вычисление кумулянтов и моментов распределения Майкснера / М.С. Токмачев // Вестник НовГУ. - 2013. - № 75-2. - С. 47-51.

2. Токмачев, М.С. Характеризация распределения типа гиперболического косинуса свойством постоянства регрессии / М.С. Токмачев // Деп. в ВИНИТИ 21.06.94. - № 1542. - В94.

3. Токмачев, М.С. Постоянство регрессии квадратичной статистики на линейную статистику / М.С. Токмачев // Вестник НовГУ. - 1995. - № 1. - С. 139-141.

4. Токмачев, М.С. Распределение типа гиперболического косинуса / М.С. Токмачев, А.М. Токмачев // Вестник НовГУ. - 2001. - № 17. - С. 85-88.

5. Lai, C.D. Meixner Classes and Meixner Hyper-Geometric Distributions/ C.D. Lai // Australian \& New Zealand Journal of Statistics. - 1982. - Vol. 24. - Issue 2. - P. 221-233.

6. Hoffman, M.E. Derivative polynomials for tangent and secant / M.E. Hoffman // The American Mathematical Monthly. - 1995. - Vol. 102, no. 1. - P. 23-30. DOI: 10.2307/2974853

7. Hoffman, M.E. Derivative polynomials, Euler polynomials, and associated integer sequences / M.E. Hoffman // Electronic Journal of Combinatorics. - 1999. - Vol. 6. - \#R21.

8. Токмачев, М.С. О числовых множествах и последовательностях в связи с распределением типа гиперболического косинуса / М.С. Токмачев // Вестник НовГУ. Сер.: Физикоматематические науки. - 2015. - № 3 (86), Часть 2. - С. 35-39.

9. Токмачев, М.С. Множество подмножеств в структуре некоторой числовой призмы / М.С. Токмачев // Деп. В ВИНИТИ 09.06.2016. - № 91. - В2016. - 90 с.

10. The On-Line Encyclopedia of Integer Sequences ${ }^{\mathrm{TM}}$ (OEIS ${ }^{\mathrm{TM}}$ ). http://oeis.org (дата последнего обращения: 5.05.2018).

11. Franssens, G.R. On a Number Pyramid Related to the Binomial, Deleham, Eulerian, MacMahon and Stirling number triangles / G.R. Franssens // Journal of Integer Sequences. - 2006. - Vol. 9, Issue 1. - Article 06.4.1.

12. Knuth, D.E. Computation of tangent, Euler and Bernoulli numbers / D.E. Knuth, T.J. Buckholtz // Math. Comp. - 1967. - Vol. 21. - P. 663-688.

13. Brent, R.P. Fast computation of Bernoulli, Tangent and Secant numbers / R.P. Brent, D. Harvey // arXiv preprint. - 2011. - arXiv:1108.0286 [math.CO].

14. Токмачев, М.С. Прикладной аспект обобщенного распределения гиперболического косинуса / М.С. Токмачев // Вестник НовГУ. - 2005. - № 34. - С. 96-99.

15. Токмачев, М.С. Некоторые интегралы, связанные с распределением типа гиперболического косинуса / М.С. Токмачев // Математика в вузе и в школе: Труды XXIV Международной научно-методической конференции. - СПб.: Петербургский гос. ун-т путей сообщения. - 2012. C. $185-186$.

16. Токмачев, М.С. Вычисление интегралов от функций некоторого класса с вероятностной интерпретацией / М.С. Токмачев // Вестник НовГУ. Сер.: Физ-мат. Науки. - 2014. - № 80. C. $42-46$.

17. Токмачев, М.С. Вероятностные распределения: от характеризации к числовым множествам / М.C. Токмачев. - Саарбрюккен: LAP LAMBERT Academic Publ., 2018. - 224 с.

Поступила в редакцию 7 декабря 20182. 